\title{
Genetic Hotspot
}

National Cancer Institute

\section{Source}

National Cancer Institute. Genetic Hotspot. NCI Thesaurus. Code C94367.

A genetic sequence at which mutations occur with an unusually high frequency. 